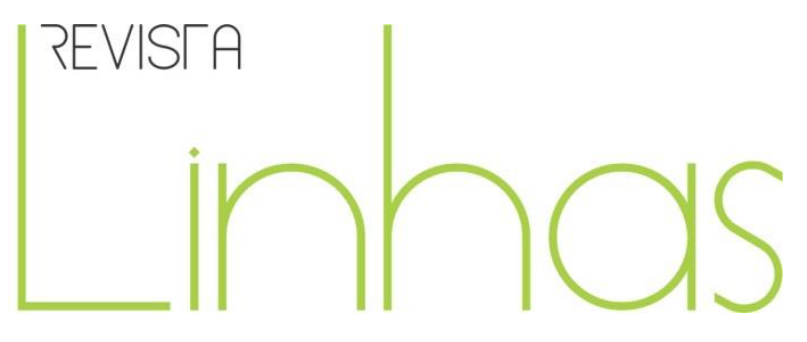

\title{
Resenha do livro "Cultura material escolar em perspectiva histórica: escritas e possibilidades"
}

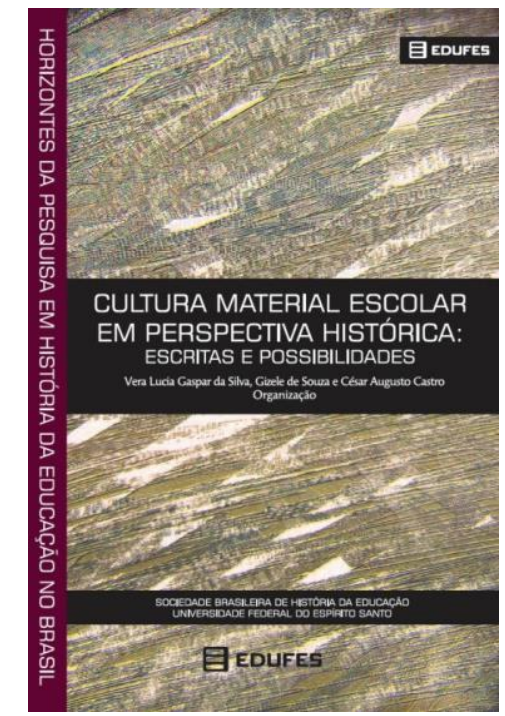

SILVA, Vera Lúcia Gaspar da; SOUZA, Gizele de; CASTRO, Cesar Augusto (Org.). Cultura material escolar em perspectiva histórica: escritas e possibilidades. Vitória: UFES, 2018. 470 p. ISBN 9788577723904.

\section{Nicholas Cardoso Gomes da Silva}

Universidade do Estado de Santa Catarina - UDESC - Florianópolis/SC - Brasil nicholascardoso1@gmail.com

\section{Para citar esta resenha:}

SILVA, Nicholas Cardoso Gomes da. Resenha do livro "Cultura material escolar em perspectiva histórica: escritas e possibilidades”. Revista Linhas. Florianópolis, v. 20, n. 44, p. 352-358, set./dez. 2019. 
A obra Cultura material escolar em perspectiva histórica: escritas e possibilidades é organizada por Vera Gaspar da Silva, Gizele de Souza e César Augusto Castro, e produzida em coautoria com a equipe de 24 pesquisadores de diversos lugares. Com prefácio de Marcus Levy Bencostta (Universidade do Paraná - UFPR) e contracapa escrita por Maria Teresa Santos Cunha (Universidade do Estado de Santa Catarina - UDESC), vem a público pela Editora da Universidade Federal do Espírito Santo - EDUFES, na forma impressa e em e-book (disponível gratuitamente no site da editora), como o $14^{\circ}$ volume da Coleção Horizontes da Pesquisa em História da Educação no Brasil. Difundindo a suntuosidade de um trabalho árduo de investigação realizado de maneira integrada e extremamente articulada, a obra promove um imenso campo de conhecimento, possibilidades de investigações e interpretações.

É fruto de muitas ideias, encontros, reuniões de pessoas e desejos, tendo sua primeira proposta em 2014, durante o encontro das professoras Vera e Gizele em seus estudos acadêmicos na Itália. Posteriormente, foram agregadas as contribuições de César, como também organizador. Outros pontos importantes para sua organização foram os seminários e projetos de pesquisas desenvolvidos pelos autores sobre a temática da cultura material, dos quais, destacam-se: I Colóquio História da Educação, Infância, Cultura Material (2015, em Curitiba), que contou com a participação de vários estudantes e docentes de História da Educação da UDESC, Universidade Estadual de Campinas - UNICAMP e UFPR; a participação no III Colloquio Internazionale sulla Cultura Materiale della Scuola: produzione, uso e circolazione di arredi e sussidi scolastici tra Europa e America Latina tra '800 e 1900 (em 2017, na Universitá degli Studi di Macerata - Itália); o projeto de pesquisa "Por uma teoria e uma história da escola primária no Brasil: investigações comparadas sobre a escola graduada (1870-1950)", coordenado por Rosa Fátima de Souza e que ultimou na participação de alguns dos autores no Grupo Temático G23 “Cultura material escolar: investigações comparadas sobre a escola graduada (18701950)"; e o projeto de pesquisa “História da escola primária no Brasil: investigação em perspectiva comparada em âmbito nacional (1930-1961)", também coordenado por Rosa Fátima, com a presença dos autores no Grupo Temático G3 "Cultura material escolar: a materialidade da escola primária graduada pelo estudo da cultura material escolar (SE, 
MA, PR, GO e SC)"; por fim, as contribuições teóricas internacionais de António Nóvoa e Agustín Escolano.

É constituído por um prefácio, um posfácio com característica de capítulo/artigo e outras 17 produções de pesquisadores, nacionais e internacionais, que trabalham com a cultura material escolar em diferentes prismas que, para os organizadores, fazem menção à escola como espaço detentor de peculiaridades únicas dependentes de culturas escolares singulares. O primeiro capítulo foi escrito pelos organizadores e é uma apresentação do livro e da materialidade escolar entre caminhos, pesquisas e diálogos.

O segundo capítulo, intitulado "A história da escola como fenômeno econômico: diálogos com história da cultura material, sociologia econômica e história social”, de Cynthia Greive Veiga, faz reflexões tendo como base as categorias: oferta/demanda escolar e a relação com a condição material. Indaga, no sentido de identificar, uma possível economia escolar e suas necessidades diante de situações de precariedade e insuficiência em todos os períodos históricos da educação. Ressalta, tendo como apoio autores importantes da área, que diante da pobreza há alterações históricas. Prossegue com reflexões sobre a importância de problematizar no âmbito da institucionalização da escola. Nesse sentido, pondera sobre as condições materiais de funcionamento, do trabalho docente e de escolarização das crianças, que também são manifestações da cultura material.

O terceiro capítulo, de Dominique Poulot, "Uma nova história da cultura material?", contribui para uma compreensão melhor da cultura material. Para o autor, o maior cuidado é investigar os objetos para entender as condutas em uma perspectiva da história social ou antropológica. Além disso, faz uma reflexão sobre a importância da materialidade, o consumo e a sua comercialização.

Já o quarto capítulo, “Etno-história e cultura material da escola: a educação nas exposições universais", de Agustín Escolano Benito, aborda as exposições universais do século XIX e começo do XX, a publicidade e visibilidade social como apresentação do mundo contemporâneo, ainda desconhecido. Muitos desses materiais passaram a ter uma grande apropriação e circulação nas escolas. 
O quinto capítulo, de Vera Gaspar da Silva e Gizele de Souza, intitulado “Objetos de utilidade prática para o ensino elementar: museus pedagógicos e escolares em debate", relata que os museus pedagógicos e escolares tiveram as exposições universais como espaços de inspiração, e os materiais apresentados pretendiam pactuar com o que havia de mais moderno no período. Outro ponto em discussão é a necessidade dos materiais, que superavam o apoio pedagógico forjando o consumo de produtos industrializados.

Dando continuidade à temática, "Escola e museu: experiência sensível e didatismo como eixos comuns", de Heloisa Barbuy, é o sexto capítulo. A relação entre museu, escola e possibilidades das exposições tem caráter demonstrativo e intuito didático.

Já a sétima parte do livro, escrita em espanhol por Cristina Yanes Cabrera e Guadalupe Trigueros Gordillo, tem como título “La patrimonialización de la cultura escolar en España: discursos y escenarios", aponta para a memória educativa e a iniciativa museográfica como teorias de interpretação que buscam características do passado nos estudos da história da educação, tentando preservar, expor e estudar os bens patrimoniais.

O oitavo capítulo, também em espanhol, "Posibles metodologías de trabajo histórico sobre la cultura material de la escuela: entre el material didáctico y los catálogos de enseñanza - primeros resultados de una investigación en curso", tem autoria de Marta Brunelli e aborda o processo inicial de produção e circulação de materiais escolares na Itália do fim do século XIX e início do XX, analisando as produções didáticas com teor científico.

“Higienismo e cultura material escolar: notas sobre a invenção dos objetos e de suas funções", de Heloísa Helena Pimenta Rocha, é o nono capítulo. Apresenta a ligação entre a materialidade e o discurso internacional médico-higienista do fim do século XIX nas escolas primárias do estado de São Paulo nas primeiras décadas do século XX.

Já o décimo capítulo, de Wiara Rosa Rios Alcântara e Diana Gonçalves Vidal, tem o título de "Corpo e matéria: relações (im)previsíveis da cultura material escolar", cujo objeto de análise são as carteiras escolares. As autoras fazem uma reflexão sobre a 
influência da materialidade na constituição das corporeidades dos estudantes, pois esta pode mostrar a projeção de conceitos e ideias.

O décimo primeiro capítulo é de Samuel Luis Velázquez Castellanos e de César Augusto Castro, tendo como título "A escola como vitrine: os objetos escolares nas exposições do trabalho no Maranhão Império". O texto faz uma análise das matérias publicadas na imprensa maranhense sobre a exibição das naturezas diferentes. Os autores questionam e retratam os objetos da cultura material escolar nas diversas edições da Exposição do Trabalho, promovidas pelo governo provincial com o objetivo de exibir a variedade de produtos da terra e as distintas práticas culturais dos sujeitos.

“Com a palavra, as carteiras escolares”, de Heloisa Helena Meirelles dos Santos e Ana Chrystina Venancio Mignot, é o décimo segundo capítulo e aborda, novamente, a questão da materialidade, tendo como fonte propulsora a carta administrativa enviada por Lourenço Filho a Anísio Teixeira. Nela, os objetos escolares aparecem como figura central da discussão a preocupação com o mobiliário adequado aos alunos. Tal objeto, a carteira, revela-se mais do que apenas um móvel: pode propor o entendimento de como se organizava a sala de aula, a disciplina, o possível método de ensino utilizado e as práticas exercidas no período de utilização, a relação professor-aluno e a "ordem moral dos corpos que ocupam os espaços físicos".

O décimo terceiro capítulo, "Objetos, imágenes y tecnologías como fuentes para la historia de la educación: reflexiones desde una práctica de investigación", é de Inés Dussel. Por meio dos uniformes escolares, a autora objetiva uma reflexão sobre as vestimentas, os rituais e o regime de aparência, como representantes de um passado em que se procurava promover identidades e corpos disciplinados de maneira homogênea. Considerando que os objetos são participantes da rede social, pode-se tentar entender a história humana como um "processo contínuo de objetivação".

“A materialidade dinâmica da educação escolar: professores, tecnologias, rotinas e trabalho", de Martin Lawn, décima quarta parte do livro, versa sobre as possibilidades que emergem quando a sala de aula passa a ser observada como a construção de uma tecnologia social. Utilizando-se da arquitetura escolar, busca pensar como tal aspecto pode contribuir para influenciar e moldar o método de ensino. A escola passou a ser vista como um campo lucrativo, capaz de absorver e propagar as tecnologias, captando e 
levando em consideração os objetivos intrínsecos da vigilância e da ordem disciplinar homogênea.

Já o décimo quinto capítulo, intitulado "A tecnologia educacional na investigação histórica da cultura material escolar", de Rosa Fátima de Souza e Rosilene Batista de Oliveira, continua a discussão sobre as tecnologias educacionais e a cultura material escolar nas pesquisas históricas, buscando compreender seu espaço e sua importância em investigações da história da educação. Expõe a abundância de objetos que compõem o contexto escolar.

O décimo sexto capítulo, de Eurize Caldas Pessanha e Fabiany de Cássia Tavares Silva, tem como título "Cultura material na escrita da história curricular de uma instituição de ensino secundário do sul de Mato Grosso (1939 a 1970): espaços, objetos e práticas”, e descreve a intencionalidade e o projeto de escolarização e modernização do ensino secundário da cidade de Campo Grande, por meio do aparelhamento escolar como condutor da qualidade da formação e incremento das práticas.

“Materialidade da escola primária no estado do Rio de Janeiro (1893-1922): entre escolas singulares e graduadas", de Rodrigo Rosselini Julio Rodrigues e Silvia Alicia Martínez, é o décimo sétimo capítulo. Os autores buscam apresentar a importância da arquitetura escolar à materialidade da escola e sua modernização. Como tais aspectos contribuem à escolarização, demonstram concepções de ensino, bem como os fins sociais e culturais da educação. Os Grupos Escolares ocupavam prédios imponentes que eram adaptados para o devido fim, escondendo as condições insalubres e precárias onde se pregavam os preceitos de higiene e modernidade.

O posfácio e último capítulo trata das "Patentes e monopólios industriais: novas fontes para uma história da indústria escolar - primeiras sondagens nos arquivos italianos (1880-1960)", de Juri Meda. O texto aponta para as potencialidades de análises históricas dos processos de escolarização, tendo como centralidade a materialidade escolar para pesquisar os aspectos culturais.

É uma leitura imprescindível, não somente para os que almejam compreender os processos históricos, mas para todos aqueles que estudam a dimensão instrumental da materialidade da escola. Os autores oportunizam no livro o encontro de trajetórias 
indefinidas de sujeitos distintos com objetos culturais semelhantes e a conexão entre práticas pedagógicas diversas, parcialmente orientadas por prescrições e normas. Ponderações foram feitas a respeito dos objetos pertinentes aos ambientes de ensino e que têm ajudado nas pesquisas relacionadas à influência mútua da materialidade com a corporeidade dos indivíduos envolvidos no processo de ensino-aprendizagem. Apontam os sentidos que podem esclarecer o objetivo de uma mediação com os conteúdos propositalmente escolhidos, além de debaterem sobre lugares fora da escola com a finalidade educacional, como museus e exposições.

Para engrandecer o entendimento e, como presente para os leitores e pesquisadores da História da Educação, a obra traz quadros e figuras, como: lista dos objetos entregues pelo diretor do Liceu de Campos ao Grupo Escolar, 1900; relação das leis de obrigatoriedade escolar no Brasil; quadro com a cronologia das exposições internacionais; relação dos museus pedagógicos criados entre 1850-1906; transcrição da lista de material recebido em 1940 para os laboratórios de Física, Química e História Natural; prédios de escolas primárias inaugurados nos governos de Nilo Peçanha, Geraque Collet e Raul Veiga (1916-1922).

Ao finalizar a resenha, salienta-se que os organizadores são docentes e pesquisadores da linha de pesquisa História e Historiografia da Educação dos Programas de Pós-Graduação em Educação das universidades as quais cada um pertence, sendo Vera Lúcia Gaspar da Silva, da UDESC, Gizele de Souza, da UFPR e, César Augusto Castro da UFPA e da UFMA.

\section{Referência}

SILVA, Vera Lúcia Gaspar da; SOUZA, Gizele de; CASTRO, Cesar Augusto (Org.). Cultura material escolar em perspectiva histórica: escritas e possibilidades. Vitória: UFES, 2018. 470 p. ISBN 9788577723904. 